\title{
Perspectives of teachers, children, and parents on the transition to first grade
}

\author{
Miriam Breuer ${ }^{*}$, Clodie Tal ${ }^{* *}$
}

\begin{abstract}
This research is a case study of a school that sought to ascertain what is required for the optimal adjustment of children to first grade from the perspective of each partner in the education triad - children, parents, and the teaching staff (teachers and assistant teachers). The research tools adapted to the participants are open-ended questionnaires to elicit the perspectives of the parents and teaching staff, and interviews of the children following their creation of a metaphorical collage to elicit their perspectives. Participants were three first-grade teachers, the assistant first-grade teacher, ten children from one of the first-grade classes, and twelve parents of these children. All the children attend a regional primary school and come from [cooperative Israeli settlements in central Israel. The findings indicate that the emotional climate of the school was regarded as positive by all the respondents. Although all respondents expressed a desire for more inter-personal communication with each other, the expectations of parents and teachers differed with respect to the desired frequency and setting limits on the communication between them. The paper also describes changes instituted to improve communication between the school and the parents in light of the research findings.
\end{abstract}

\section{Article History}

Received: 11 September 2019

Accepted: 13 November 2019

\section{Keywords}

Transition to first grade;

Parental involvement;

Children's perspectives;

Parent-teacher collaboration;

Listening to parents and

children

\section{Introduction}

This research sought to gain insight about what is required to facilitate the adjustment of children to first grade from the perspective of each participant in the education triad - children, parents, and the teaching staff - and to understand the prevailing relations. In particular, we wanted to learn how each participant in this triad perceives his or her own role and the role of the other in the child's adjustment to first grade. For this research, in keeping with the ecological systems theory of Bronfenbrenner, a role is defined as "a set of activities and relations expected of a person occupying a particular position in society, and of others in relation to that person" (1979, p. 85).

To that end, research tools suitable for each participant were used: open-ended questionnaires to the parents and teaching staff to elicit their perspectives, and interviews of the children following a metaphorical collage they prepared to elicit their perspective.

The transition of children from preschool to first grade is experienced by parents with a mixture of joy and fear, aware that the start of formal education is the foundation for learning and personal growth. Parents bring with them memories of their own lives, the experience of raising children, and imprints of relationships with preschool teachers and caregivers prior to their child's entry to first grade - a mix of trepidation and expectation. Teachers bring to the first grade, besides their professional expertise, their experiences of relationships with parents in the past, expecting to be able to construct a new and positive set of relations with the new class. Young children with a character set of their own bring varied experiences from their preschools. They are happy and fearful, still processing their separation from the preschool teacher and perhaps also from friends who remained behind, and they too hope for and expect a positive experience.

\footnotetext{
Levinsky College of Education, Faculty of Education, Early Childhood Education, Tel Aviv, Israel, miriambreuer@gmail.com, ORCID: https://orcid.org/0000-0002-0306-0071 " Levinsky College of Education, Faculty of Education, Early Childhood Education, Tel Aviv, Israel, clodietal@gmail.com, ORCID: https://orcid.org/0000-0002-3047-1642 
In light of the importance of understanding the perspectives and relationships of the participants in their "natural" context, the ecological-systems theory of Bronfenbrenner (Bronfenbrenner and Morris, 2006) was selected as a theoretical approach to guide the planning of the research, analysis of the data, and communication between the teaching staff, parents, and children. This microsystem is evident in the daily interactions of the child with his or her parents and teachers within the physical space of the home and school - the developmental context closest to the child -proximal processes that affect the child's development. These relations are also affected by the traits of the child, the parents, and the teaching staff (the perceptions and expectations studied in this research are included in the traits of the "Person"), which ultimately affect the development and adjustment of the child. Relations between the children and their teachers are also affected by the "Context" dimension, which includes the interrelations, cooperation, and coordination between the parents and teachers (relations situated in the mesosystem), each of which has a direct connection to the child in terms of Bronfenbrenner's original model (1979). The context also embraces specific geographic and cultural characteristics of the parents and teachers in each framework. In this study, for example, many of the families live in cooperative Israeli settlements at some distance from the school, and therefore the children require transport to school. Social and power dynamics in society between parents and teachers are among the macrosystem factors that indirectly affect the child's development (Addi-Raccah and Ainhoren, 2009; Addi-Raccah, Amar, and Ashwal, 2018). Moreover, the "Time" dimension in the early twenty-first century affects relations both on the level of daily planning in school and home and, correspondingly, on the level of contemporary life when technology dramatically affects communication options between people, even parents and teachers (Schechtman and Busharian, 2015).

School is an organization in which its officials stand in power relations with each other and with the parents. In addition, as found by Addi-Raccah and Ainhoren (2009), the balance of power between the establishment and the teachers and parents - more precisely, the relative power of each group - affects how teachers perceive their involvement with the parents. An equitable balance of power between the parents and teachers correlates with teachers' positive attitudes toward the involvement of parents in school life. The power balance between parents and teachers has shifted dramatically since Israel became a state. In the early years, teachers were perceived as the ultimate school authority, and parents were kept out of school decision-making; today, parents wield a decisive influence on their children's education (Erez, Bienstock, and Lukes, 2005) and what happens in the schools (Bronfenbrenner and Morris, 2006; Friedman, 2010; Greenbaum and Fried, 2011; Tal and Bar, 2011). Beyond the ecological approach, this research takes the view that children are full members of society and entitled to their own basic human rights, besides being part of their families (Britto, 2012; Dahlberg, Moss and Pence, 2013, p. 52; Dockett and Perry, 2014). Hence, we also examined the perceptions of the children entering first grade as well as the perceptions and expectations of their parents and the teaching staff about their transition into primary school.

\section{An Ecological Systems Approach to Parental Involvement in the Transition to First Grade}

A transition such as that from preschool to primary school is an inevitable situation that can be experienced in various ways. Transitions are challenging because they are often linked to changes in an individual's appearance, activity, status, general functioning, and, in particular, social functioning. What's more, the changes may be associated with the use of physical and social space and may impinge upon cultural beliefs and educational practices that have repercussions for an individual's sense of identity - in this case, a child entering first grade (Vogler, Crivello, and Woodhead, 2008). The research presented here focuses on the perceptions of the parents, children, and teaching staff at the beginning of first grade, immediately following the transition of the children from preschool into primary school, conducted from an ecological systems approach, as noted, and in keeping with UNICEF's conceptual framework of school readiness (Britto, 2012) and the position paper of the Australian Ministry of Education concerning transition to school (Dockett and Perry, 2014).

The transition of children to school impacts their learning and development (Hughes, Luo, Kwock, and Loyd, 2008; Sayers et al., 2012). A successful transition to first grade fosters the child's positive attitude to school, a sense of belonging, and active participation in what happens there (Dockett and Perry, 2009; 2014). 
Perspectives of teachers, children, and parents on...

The child's family and educational frameworks, in addition to his or her characteristics, can affect how the child copes with transition (Britto, 2012; Dockett and Perry, 2014). Forcing children to cope without support or protection, for example, could diminish their competence in handling transitions in general.

The educational institution provides opportunities for learning, and the family provides the scaffolding of support to the child in transition to complete the process of adjustment to a new framework. In this process, children also shape attitudes and expectations about their own ability to grapple with learning tasks (Dockett and Perry, 2014; Erez et al., 2005; Plotnik and Eshel, 2007). Furthermore, parentschool relations and partnerships are likely to influence the children's adjustment to the school environment, their wellbeing, and learning (Acar, Veziroğlu-Çelik, Çelebi, İngeç, and Kuzgunet, 2019).

Upon entering first grade and separating from the preschool, the child is expected to have a higher level of independence. This is a transition to a more achievement-oriented system, and therefore preschool teachers and parents worry about the fate of some first graders. The process can be facilitated by providing more information about school and opening the channels of communication between the preschool and the primary school; when a child is prepared for the transition, it becomes an opportunity for growth (Dockett and Perry, 2014; Plotnik and Eshel, 2007).

In short, how the transition to first grade is handled greatly affects the sense of belonging, learning, and development of children, as well as their involvement in school activities (Dockett and Perry, 2014). A successful transition depends not just on the child's characteristics, but also on the quality of the relationships between the parents and teachers, the parents and children, and the teachers and children (Bronfenbrenner and Morris, 2006; Dockett and Perry, 2007, 2014; Pianta, 1999; Vogler et al., 2008). Based on the ecological systems approach to teacher-parent relations (Bronfenbrenner, 1986), Walker and HooverDempsey (2015) emphasize the need for each party to understand the perspectives of the other - that the parents understand the perspective of the teachers and children, and the teachers understand the perspectives of the parents and children.

Thus, the research presented here sought to ascertain what actually transpired and what is required for the successful adjustment of children to first grade from the perspective of each party to the education triad - children, parents, and the staff (teachers and assistant teachers). In particular, it sought to understand how each perceives his or her own role and the role of the other in the process of the child's adjustment to first grade.

\section{Research Questions}

- How do the parents, children, and teachers in the school grasp their own role and the role of the other in the effort to create a good and supportive relationship during the child's first year of primary school?

- What are the parents' expectations of their children's teachers as the children begin first grade?

- What expectations do the teachers have of the first graders' parents?

- What are the children's expectations of their parents' involvement in the school?

- What are the children's expectations of their teachers in general and specifically the teachers' relationship with their parents?

- In the opinion of the parents and teachers, how can the children themselves contribute to their adjustment to school and success at their studies?

Method

\section{Type of Research}

Case study methodology was used to derive answers to the research questions. In this method, an in-depth study is conducted of a social or organizational phenomenon in a real-life context, particularly in cases where the boundaries between the phenomenon and its context are not clearly demarcated (Yin, 2009, 
p. 18). Case study methodology was used here to ascertain the perceptions of the teachers, parents, and children about the transition and adjustment to first grade. This type of research is rich in data and requires multiple sources of evidence to enable triangulation of the data. Furthermore, the methodology rests on theoretical assumptions, such as the ecological systems approach, which underpins this research. A qualitative analysis of the data allows for a broad and detailed examination of the phenomena, and brings into view a range of diverse findings and perspectives. One of the advantages of qualitative analysis is that it enables the linkage of findings and theory in a rich and compelling manner (Shlaski and Arieli, 2001). Research of this type also allows for a description of the respondents' reality as it is perceived by them.

\section{Respondents and Field of Research}

Research was conducted in the first grade of a public, regional primary school ( $1^{\text {st }}$ to $6^{\text {th }}$ grades) serving several cooperative Israeli settlements. Some of these children live at a distance from the school, and therefore require transport to and from the school, which raises concerns for many parents. This is a relatively big elementary school, serving 825 children at the time of the research (three classes at each age level). As part of the school's vision, student entrepreneurship is encouraged - students are advised by experts to develop and sometimes sell various products. Thus, the school encourages students to dare, think, invent, make mistakes, and be critical of ideas at the expense of the quantity of contents processed. To that end, the school partners with experts in education, ecology, business technology, and the arts. Children's parents are also involved either at the stage of idea development or as experts.

Ten children - six girls and four boys - twelve mothers, three first-grade teachers, and one first-grade assistant teacher participated in the study. The participating children and their parents are all part of the class led by the first author as a first-grade teacher.

The children: To grasp the children's perspectives, ten of the most expressive and articulate girls and boys in the class were selected to participate in the study, out of 32 children in total in the class. The students selected were those willing to share their thoughts and feelings with an adult and willing to have a group conversation. They are also students who spend more time touching creative materials and engaging in artistic work. Six of these children get to school by the bus belonging to the regional council's transport system, while the other four live in the cooperative settlement where the school is located and go to school on foot or by bike, alone or accompanied by a parent. Distinguishing between children who come by bus and those who live near the school is significant in light of the concern shown by some parents and children related to the daily use of bus transportation to and from school. This is an issue with which some children and parents have to grapple upon entering first grade.

The parents: Questionnaires were distributed to all the parents of the class studied. Twelve of the 32 mothers in the class responded, all of whom were married, have professions, and hold down a job. Nine mothers live in this regional council and their children use the organized transport to get to school; three mothers live in the cooperative settlement in which the school is located and their children do not use the bus to get to school.

The teachers: All three first-grade teachers in the school during the year of the research were interviewed. Two had over twenty years of experience and one had three years of experience. The assistant teacher of first grade had served in this position for six years. One of the teachers who participated in the study is the first author of this study.

The names of all participants in the research, the name of the school, and its location remain anonymous; names used in this paper are fictitious. The parents of the children gave consent to participate in the research. The children were also asked for their consent, which they gave both orally and by signing their name; they were also told that they may opt out of the study at any time.

As noted, the first author of this paper was herself a first-grade teacher in this school and conducted interviews as part of this research. Being a teacher may have been helpful in the good relations she has with the respondents; on the other hand, being a teacher could adversely affect the openness of the respondents in expressing their views. In retrospect, the findings indicate that the participants expressed both positive 
and negative views about what transpires in the school.

\section{Research Tools}

To understand the perspectives of the various respondents, we interviewed the children following their creation of a metaphorical collage and administered partially open-ended questionnaires to the parents and teachers. Data were collected in January and February 2014. The data obtained in the study, as shown below at the end of the Findings section, catalysed changes in how the school management and teaching staff collaborated with children's parents. These changes are still in effect in 2019. Furthermore, the approach adopted in this study of taking an interest in the expectations that children, parents, and teachers have for each other required that the school learn about these expectations and find ways to take action to meet the stakeholders' needs.

\section{Details about the research tools.}

1. Interviews with the first-graders following their metaphorical collage. This tool makes use of visual language as the child creates images that can shed light on his or her perspective about the subject of the collage. In this activity, the children are engaged in reflection both during and following the creative act (Russo-Zimet, 2016). The children are already familiar with and enjoy creative activity. The researcher places on the table newspapers, magazines, and other accessories such as scissors, a stapler, colours, and paste, and gives the children the following instructions: "On the table are various materials. Use these materials to express the subject, 'I am in first grade, my parents and my teacher' in any way you choose." While the child is working, the researcher does not converse with him or her or intervene in any way to avoid influencing the child's creation. If the child addresses the researcher, she approaches the child and responds directly to the question. The child must be allowed maximum freedom of expression and reminded of the instructions and the permission to use additional materials. After completion, the child is asked to explain the collage that is the product of his or her creative activity. Discussion between the researcher and child leads to exposure of the thought underlying the collage and strengthens the personal connection between the researcher and the child. All discussions with the children were recorded and transcribed. A photograph was also taken of each collage.

Below we present an example of a metaphorical collage (Figure 1) and an interview following it. Upon completion of the collage, Alon titled it, "A Visit to First Grade."

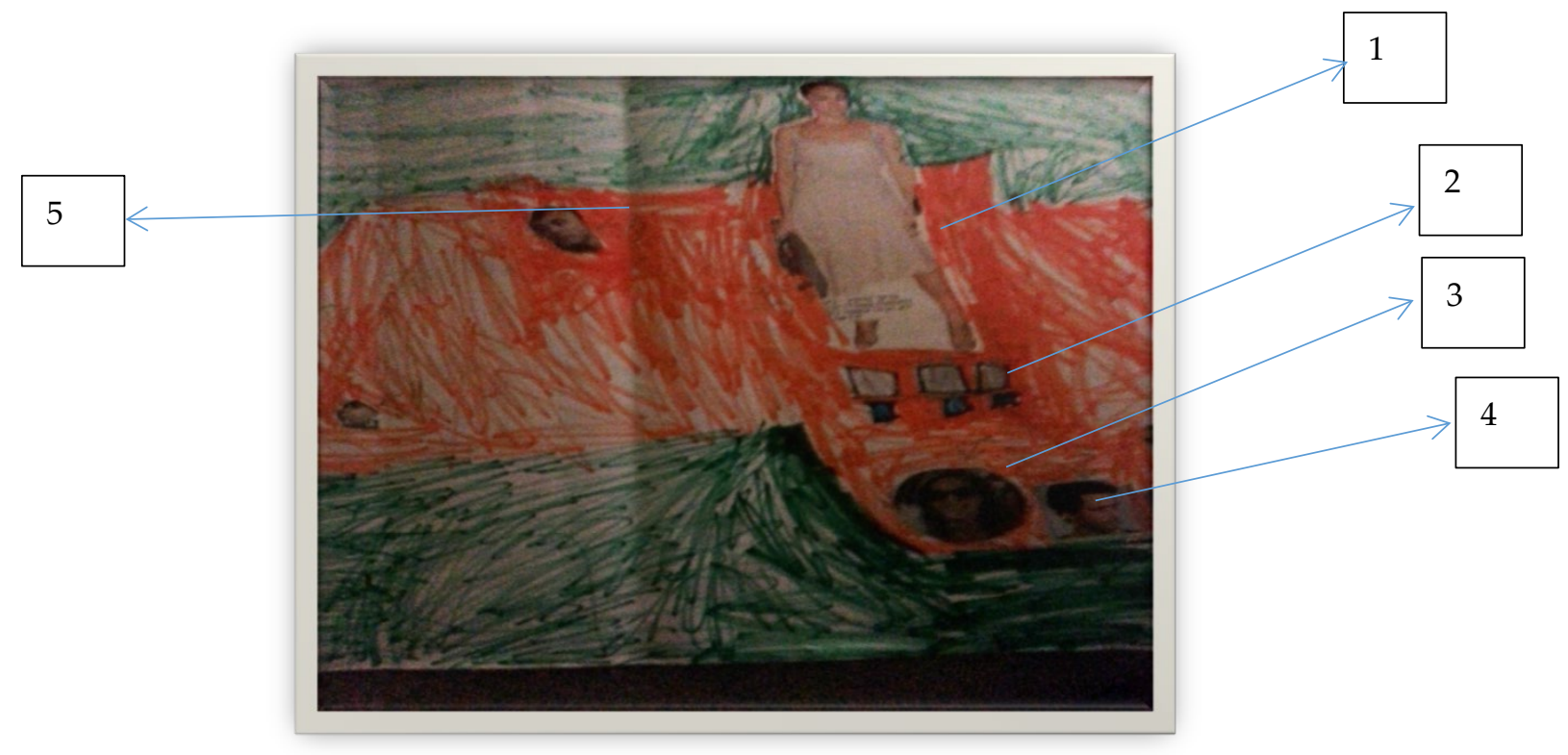

$1=$ my teacher; 2 = the classroom; $3=$ my mother; $4=$ my father; $5=$ my brother

Figure 1: Alon's Collage: "A Visit to First Grade" 
The interview with Alon:

First of all, I like being here [in school], especially recess. A second thing, my mom...Wow! It's hard...I don't have, don't know what to say. Three, my dad. Sometimes he makes me angry and sometimes he teaches me important things. Four, my brother, he's cute. Five, you, the teacher. That it's fun that you're teaching me. Six, my big brother. He always bothers me and he also gets me angry with his blade and that's it."

The researcher (the boy's teacher): Can you tell me about first grade and the roles of the people involved?

Yes, Mom makes sure to remind me every day if I forget my schoolbag, she reminds me to take it. Dad makes tea for me in the morning so I won't be hungry in the bus. My little brother reminds me that I have school. The teacher teaches me. I put you in the classroom and them [the parents] in the workshop a little in the classroom, they're not exactly there. I feel them in my heart.

2. A partially open-ended questionnaire administered to the parents of the first-graders. The parents were asked to write about their perceptions and desires concerning their children's transition to first grade and the relationship they would want with the teachers. Examples of questions: "In your opinion, what would be a very good relationship between you and the school?" and "What is a successful transition from preschool to first grade, in your opinion?"

3. A partially open-ended questionnaire administered to the first-grade teachers. This was designed to elicit the teachers' perception of the roles of the parents, the children, and themselves in the transition of the children to first grade. Examples of questions: "What can you do as a teacher to ensure a smooth transition and successful adjustment of the children to first grade?"; "How do you think the children regard the transition from preschool to first grade?"; "What do you think the child expects of his teacher?"; and "What do you think the child expects of his parents?"

4. A questionnaire to the assistant teacher of first grade had the same level of detail as the questionnaires to the other teachers.

A pilot test to establish the content validity of the open-ended questionnaires for parents and teachers was conducted. This was administered to approximately $23 \mathrm{M}$. Ed. students in an Early Childhood Education research class at Levinsky College of Education. The students were preschool or first- and second-grade teachers completing their M. Ed. degree in Early Childhood Education. About half the students filled out the questionnaire as teachers and the other half were asked to fill it out as parents (they themselves were also parents). In the second stage, the students were asked for feedback and suggestions about the content and structure of the questionnaire itself. Based on the pilot test and feedback, the questionnaires were modified and finalized. In the research itself, data from the responses of the teachers, assistant teacher, parents, and children were triangulated to enhance reliability.

\section{Data Analysis}

A content analysis was conducted of the responses to the questionnaires and interviews with all the respondents, including the interviews with the children following the metaphorical collage. An inductive approach to category development was adopted as categories were directly extracted from the data (Mayring, 2000). The content analysis led to the identification of three categories underlying the texts, which emerged as subjects that study participants regarded as critical in the adaptation of children to first grade:

1. Emotional climate in the home and classroom environment with reference to (a) the climate that exists; and (b) the desired climate.

2. Parental presence at school, which included two subcategories: (a) the physical presence of parents in the classroom; and (b) parental presence as part of ongoing non-face-to-face communication with the school and educator (via telephone or digital media).

3. Interpersonal relationships as a basis for building trust, strengthening security, and creating a learning environment.

Transcriptions of the interview and questionnaire responses were then broken down into statements 
Perspectives of teachers, children, and parents on...

that were categorized according to the above three categories and subcategories related to the mutual perceptions about the roles of parents, teachers, and children during adjustment to first grade. Categorization was initially performed by the first author and then independently by the second author. Inter-judge agreement between the two authors on attribution of statements to categories was high (around $90 \%$ ) and disagreements were subsequently resolved.

\section{Results}

Analysis of the interviews with the parents and teachers and of the post-collage interviews with the children revealed three main subjects on which the participants focused as promoting successful adjustment of the children to first grade:

1. The emotional climate in the home and classroom

(a) the current emotional climate

(b) the desired emotional climate

2. The presence of parents

(a) physical presence in the classroom

(b) indirect (not face-to-face) communication with the school or teacher (by telephone or digital media)

3. Interpersonal relations as the basis for building trust, enhancing security, and creating a learning environment

\section{Emotional Climate in the Home and Classroom}

The current emotional climate. The emotional climate relates to the feelings shared by the members of a community or organization and is closely related to the quality of relationships among the people involved (de Rivera, 1992). Emotional (positive and negative) climate was therefore included in the Classroom Assessment Scoring System (CLASS) by Pianta, LaParo and Hamre (2008) The children, parents, and teachers all addressed in their responses and evaluated positively the current emotional climate in the home and classroom. The children's interviews following preparation of the collages also reflected positively on the classroom and good relations with the teaching staff. Some respondents included aspects of learning (such as stating that it is fun to learn) as components of the classroom climate. That is, some children indicated that they were eager to learn and that experiential learning contributed to the positive climate of their classroom, while others perceived social encounters during recess as most contributing to the positive emotional climate of the school. A few linked the positive climate at home with the positive climate in the classroom, reflecting on how they view the environments in which they live.

Responses from the children. The following excerpts were extracted from interviews with the children explaining their collages. The children's descriptions of the positive climate in the classroom were spontaneous and not elicited by the interviewer's direct questions. Alon stated, "First of all, I like being here, especially [I like] recess." Noy commented, "I like being in first grade, the lessons are fun, and I enjoy it here." Noga talked about the pleasant atmosphere during classroom learning, illustrated by noting, "things that children in first grade like - costumes, wigs."

Responses from the parents. The parents' responses showed that they are aware of their responsibility in ensuring a good climate in first grade, and want to be involved in creating it. The mother $\mathrm{Na}^{\prime}$ ama emphasized the importance of the parents' contribution to creating a positive emotional climate in class: "Parents should ask: How was it during the recess? How was it in the classroom? How does the teacher treat the children?"

Responses from the teachers. The teachers' responses show that they are aware of the emotional needs of the children and see themselves as responsible for creating a positive climate in their classrooms. One of the teachers stated, "I lay the groundwork, prepare a beginning that will be pleasant and helpful, 
play with them [the children] a lot while instilling good work habits.".

Nevertheless, one can see that the teachers are critical toward some aspects of the home environment, though they are not self-critical. Nira, a teacher with many years of experience teaching first-graders, observes, "Sometimes contradictions appear between the home and the classroom...".

In contrast, the parents praise the school for creating a positive climate. The mother of one child exclaimed, "The daily update on the website is wonderful! I don't know what I would do without it.". This indicates the importance that parents attach to having information about what takes place in school. The availability of this information contributes to a positive atmosphere.

The desired emotional climate. Analysis of the data showed that the participants addressed the desirable emotional climate at home and at school as facilitating wellbeing and learning:

Parents addressing emotional climate at home. Parents talked about the desirable climate at home to support the children's learning: One mother, Noam, whose oldest child, a daughter, is in first grade, stated that it is the parents' role "to give space to talk about fears and expectations from school... One should also support the children in preparing homework."

Parents addressing emotional climate at school. In relating to the school climate, parents focused on content related to both emotional and pedagogical aspects of how first grade should be conducted. They stated that the teachers should address many needs. The mother Noam stated that "good relations with the parents, meetings with the child, being sensitive to the child [are needed for adaptation to school]" (emotional aspect). According to Donna, the mother of a middle child now in first grade, learning should be "flexible experiential learning...mediating, explaining, cooperating, flexibility in seeing the effect of the transition on each child" (pedagogical aspect).

The parents related to the children's feelings and needs at home and at school, the learning process, and the children's progress. They also related to what is desirable in relations with the teachers, not just the current relations.

Responses from the teachers. The first-grade teachers expressed their opinions about the desirable climate in first grade: The teacher Tali noted that what she and the parents experience at the beginning of first grade is important: "The parents should feel comfortable approaching me." Iris, the teaching assistant, reflecting on the atmosphere in the class, said, "There must be cooperation, meetings through the course of the year."

Summary of findings related to the desired climate in class. Most references to the school climate by the children, parents, and teaching staff were positive. The respondents described the positive climate as the product of close relations that allow for frank communication between the parents and teachers. The children expressed positive feelings toward their parents and teachers, and their expectations differ little. The parents appear to be taking responsibility for being involved and are willing to contribute to the formation of a positive emotional climate in the class. In addition to parents and teachers agreeing about their perception of the classroom climate and what engenders it, parents wanted to express their views about how the class is managed, while the teachers are sometimes critical of what happens at home. Yet not one of the participants, it should be noted, proposed a specific mechanism to discuss the issues in disagreement.

\section{The Presence of Parents}

The children, parents, and teachers underscored the importance of parental presence in school as a main factor affecting children's adaptation to this new environment. Analysis of data showed that participants mentioned two types of parental presence in first grade: physical presence in school and indirect - not face-to-face - presence through telephone or digital communication between the parents and teaching staff. 


\section{Physical presence in the classroom.}

Perception of the children. Analysis of the data suggests that the children feel a need for the physical presence of their parents in the school. Gal, the oldest child in her family, describes a desire for involving her parents in her learning process: "I want them to come more because it's fun to hear what the teacher says about me [to my parents]. They should see the things I made." During the process of adjustment, the children developed coping mechanisms to deal with the desire for their parents to be physically present and the fact that this does not routinely take place. Alon says that he feels his parents in his heart: "I put you in the classroom and them [the parents] in the workshop a little in the classroom, they're not exactly there. I feel them in my heart." Galia is beginning to demonstrate her ability to separate from her parents for a longer period of time. She is independent in her new role as a first grader. Galia and Alon make note of the separation: "I go to school, they [the parents] go to work, and I'm in school."

In short, the children express a need for the physical presence of their parents, without specific mention of when they should be present (prior to the schoolyear, during the initial school period, or throughout the year). Also, the children displayed two types of conscious mechanisms for coping with the physical absence of their parents: (a) thoughts that enable the children to symbolically feel that their parents are near them; and (b) development of a relationship with the teaching staff and other children as a way to enhance their emotional security.

Perception of the parents. With regard to a physical presence in the school during the transition period, the parents feel it is important to accompany the children prior to the start of studies and during the first days of school. Gili, mother of a second son in first grade, says, "It's good to accompany them physically at first." Ayala relates to the bus trips: "He [my son] was frightened of the trip [by bus]. He was afraid he wouldn't get on the right bus, he wouldn't know the way home, he wouldn't know where to get off."

Analysis of the parents' questionnaires indicates that the parents view their physical presence as important for a smooth transition - prior to the school year and during the initial period in school. The parents expressed a need for physical closeness, especially since the children go to school by bus. Bus trips are perceived by some parents as a particular difficulty, and grappling with this issue is shared by most of the children and parents. This is not relevant for the children and parents who live in the community where the school is located.

Perception of the teachers. The teachers also mentioned the need for the physical presence of parents in the classroom primarily prior to the beginning of the school year. The teacher Ronit stated, "The parents should visit the school during the preparatory phase of transition to first grade.". Nira, also a teacher, attests that the presence of parents is important during the transition from preschool, which includes a visit by them to the school. Iris, the assistant teacher of this grade, comments about the presence of parents, initially through communications media. Her meeting with parents is limited to specific events "and I am very happy to meet them [the parents] on school trips and special events. It's as if we all know each other already."

The teachers cited the importance of the physical presence of the parents as their children get to know the new physical setting or environment and new people. They were referring primarily to the period prior to the start of the school year, but the children expected physical presence of the parents throughout the year.

The findings on this subject can be summarized by saying that the children express a desire for the physical presence of their parents more than the parents themselves or teachers do. The children would like to see their parents in their classroom throughout the school year, whereas the parents and teachers perceive parental presence in school as important before and at the beginning of the school year.

Indirect presence - telephone and digital communication with the school or teacher. Analysis of data shows that parents' presence is evident in frequent communication between the parents and teachers via telephone or email, not only by face-to-face encounters. Yet data show that parents and teachers hold 
different attitudes toward the desirable frequency of telephone conversations.

Attitudes of the parents. Analysis of questionnaires shows that even when everything is going smoothly in school, the parents feel a need for frequent contact with the teachers, both for the exchange of information and as the basis of forming and maintaining a good relationship. Hila, one of the mothers, complained that communication with the first-grade headteacher is much less frequent than the daily communication with the kindergarten teacher: "Missing is the daily encounter." Noam sees the importance of "having long conversations, passing on information, having meetings in transition to first grade, parent guidance, and getting to know the headteacher.". Adi, the mother of a first-grader, asks for "teacher accessibility.". She expects her to be "responsive to requests and questions.". Ayala adds, "And reporting to parents is crucial.". Sima, the mother of a daughter in first grade, says:

For me, the relationship with the school staff should not only manifest itself in the event of difficulties. [At present] there is no regular meeting on a monthly basis or any regular communication if everything is going smoothly. A good relationship is based on continuous interactions, even if there are no problems; a good relationship would even mean individual emails with two or three pieces of information.

Attitudes of the teachers. Analysis of the data indicates that teachers do not always consider telephone conversations appropriate. Ronit, a first-grade teacher, notes that in order to strengthen the relationship with parents, "it is important to use a variety of communications media. Telephone conversations are sometimes inappropriate when the subject is not important, and they [the parents] sometimes cause conflicts between the home and classroom.". The teachers are much less enthusiastic than the parents about frequent communication between them. While acknowledging the need for contact, the teachers want to set the limits in advance about how and when this takes place. Nira the teacher also says that communication is important, but within limits. She feels that the rules about this are not clear, and that parents do not always respect existing rules. She writes in the questionnaire that the parents must "respect the communications rules that I set.".

In summary, though both parents and teachers recognize the importance of ongoing, open communication between them, parents show the need for frequent and regular conversations with teachers, while the teachers see the need to set boundaries on the amount and the media used for the communication. The parents, teachers, and children all cite the importance of the physical presence of the parents during the first year of school to facilitate adjustment, enhance the child's sense of security, and cope with travel by bus, which is part of the transition from preschool to primary school. While a physical presence is regarded as critical by all the adults during adjustment to first grade, the need for regular communication via the media (particularly telephone conversations) is desired primarily by the parents and not the teachers.

Ongoing contact via the media replaces the physical presence of the parent, and the preferences for frequency and type of media vary from parent to parent. Such communication serves a range of purposes: exchange of information about the child, guidance to the parent, and fostering authentic relations based on trust between the parents and teachers. Relatively more children than teachers or parents emphasized the importance of the parents' physical presence in the school. And yet the children find ways to cope with not having their parents physically present, whether through internal, symbolic means (thoughts about the parents being "in my heart") or by forming good relationships with alternative figures (teachers or other children).

The parents and teachers concur that communication is important for building relationships and fostering cooperation. The parents refer to communication with the teacher as a response to many needs, and they expect more regular contact than what currently exists, expressing the desire for frequent updates and use of all the communications media. While the teachers also view contact with the parents as an important component of their relationship and cooperation, the teachers cite the need for boundaries and rules, conventions that must be respected, and even how the parents should make contact. This issue reveals disparities in the expectations of the parents and teachers, and lack of clarity about boundaries and how to make contact. 
Perspectives of teachers, children, and parents on...

\section{Interpersonal Relations as the Basis for Building Trust, Enhancing Security, and Creating a Learning Environment}

The need for an interpersonal relationship as the basis for building trust, strengthening a sense of security, and fostering a learning environment appears in the responses that refer to qualities such as trust and openness. The children, parents, and teachers all relate to the nature of their relationships with each other.

The emphasis of the children seems to be on having a close relationship with the teacher, which provides a sense of security. In Alon's words, "It's fun that you're teaching me.". Yarin's drawing of the teacher shows her with open arms and a wide smile at the entrance to the classroom. Gal notes, "it's fun to hear what the teacher says about me [to my parents].".

The parents view their relationship with the teachers as a tool for information exchange and trust building; they cite the need for openness by the teachers, and assert that trust between the parent and teacher allows the parent to approach the teacher for information and guidance.

Donna, the mother of a middle child in first grade, says, "A first grader needs warmth and individual attention, therefore it's important that the staff have a one-on-one meeting with each child. They can see who the child is and allow him to forge ahead in what he's good at.".

The teachers emphasize that trust between them and the parents is critical to a good relationship. As Nira the teacher notes, "The relationship can be meaningful if they [the parents] feel comfortable coming to me about issues concerning their children, and if I feel comfortable turning to them about the progress of their child, whether good or bad.". Tali, another teacher, also addressed the need for openness with the parents, "A good relationship is one in which the parents see me as an empathic listener.".

The teachers' perception of the relationship with the parents is also based on experiences that were not always positive. Tali asserted that the parents "must accept my opinion as authoritative, agree to share honestly, respect the norms of conduct I set, and behave with mutual respect.".

The children perceive the relationship with the teacher to be an emotional attachment, one that allows for a learning relationship and fosters a sense of personal security and physical closeness. Statements by the parents and teachers indicate that they all ascribe importance to a trusting and open relationship. Nevertheless, expectations between the parents and teachers differ about how the contact should take place, and this could undermine the quality of the relationship. Parents expect to receive ongoing updates, information, support, and guidance. The teachers note the different expectations between them and the parents with respect to telephone calls - the manner, timing, and frequency of contact with parents are not always consistent with accepted norms or the level of importance of the subject.

Teachers appear to view information provision to parents as part of their job, but they do not see themselves as parental guides or supporters, even though parents mentioned this as a need. Though both teachers and parents note the importance of regular contact and a good relationship in order to create the optimal climate in the classroom, teachers propose setting limits and rules about it, and are more critical of the parents at this early stage than the parents are of them. It also appears that teachers are willing to be perceived as the authoritative partner in the relationship with the parents - the person who sets the rules about communication between them.

\section{Summary of Findings}

The parents, children, and teachers agree on several points: The climate in the classroom and home is of critical importance as these are the main environments where the partners develop and the processes of adjustment and relationship-building take place between the children and teachers, and between the teachers and parents. The interpersonal relationships and communication with parents via physical presence or indirectly are subjects that the children, parents, and teachers all cite. Disagreements appear concerning the frequency and manner of communication between the parents and teachers, and this issue is not discussed or addressed in either formal or informal frameworks. Parents and children are looking 
for a more profound partnership, while the teachers speak about the boundaries between involvement and interference. In addition, teachers perceive themselves as the senior partner in the relationships with parents. Informal meetings with the teaching assistant are important for building the connection between the school and the parents, and creating a positive emotional climate in the school.

The findings indicate that all partners to the education triad in the first year of primary school confirm that a positive emotional climate fosters learning. The findings also indicate that this school maintains good relations with the parents and children.

What happened after completion of the study? After this research was complete and following personnel changes in the school administration, the first author initiated broad-based changes in concert with other staff members (teachers, school counsellor, and principal), parents, and students to address the needs that came to light in this research. This team, comprised of the school counsellor, the teacherresearcher now assistant principal, and the first- and second-grade coordinator, added the preschool teachers to the team of stakeholders whose perspectives and perceptions should be considered in order to create optimal adjustment conditions for the preschool children starting first grade.

Regarding the involvement of the parents, their physical presence in the school, and communication between the parents and teaching staff, many activities were introduced in addition to what had been done prior to the research. These actions involved the entire teaching staff and parents, and included:

- Meetings of the school counsellor, the principal, and the assistant principal for first and second grades with the parents in their communities during the summer vacation or before their children graduate kindergarten in order to clarify and coordinate expectations.

- Parents who wish to talk with the school staff personally are invited to meet with them prior to the start of the school year.

- The teaching staff updates the parents about what takes place in the classroom both in a class internet forum and personally by email or phone concerning the functioning of individual students.

- An evening roundtable is held once a year with the participation of teachers and parents to discuss subjects of concern to all (homework, educational innovations, etc.).

- Parents are invited to teach a class as experts in their fields, and to volunteer in the library on Fridays. The intent is to increase the physical presence of parents in the school in response to the needs articulated by the children.

- To increase the involvement of parents, activities were defined in diverse areas, such as taking responsibility for being in contact with the parents in the communities, inviting parents interested in educational innovations to learn about them and help introduce them to the classroom, etc.

- These initiatives come from both the teachers and the parents. In 2016-17, parents replaced the teachers on Teacher's Day, giving them a "different" type of morning, and this was made a permanent event by decision of the school staff and parent representatives at the beginning of the subsequent school year.

- Regarding bus transport, a task force was created to include representatives of the parents from the communities, a transport coordinator, and older students who serve as bus monitors. Bus rules were written that give special attention to the youngest students boarding first. Changes were made in the bus parking area to improve the conditions for students waiting for buses. These changes were adopted in response to the needs of the parents revealed by the research and also following requests by sixth graders in the school.

\section{Conclusion and Discussion}

The present research focused on how parents, children, and teachers perceive their own role and the role of the other in an effort to create a successful and supportive relationship in the children's first year of school. The researchers sought to understand the perceptions and perspectives of the parents and teachers 
Perspectives of teachers, children, and parents on...

based on the assumption that the successful adjustment of first graders is also contingent upon good relations among the partners - children, parents, and the teaching staff. This research therefore also takes into consideration the voices of the children so that a work plan can be designed that meets their needs. It should be noted that the preschool teachers who took part in preparing the children for first grade are also partners to the process, but their perspective about the adjustment of the children to first grade was not examined due to time constraints.

An analysis of the interviews and questionnaire responses found three interrelated issues that are of concern to the first-grade children, parents, and teachers: the classroom climate, parental presence, and interpersonal relations.

Because parents and teachers have a common interest in promoting the children's development, it is not surprising that the research participants have similar perceptions. The findings indicate that all the participants - parents, teachers, and children - agree that there is a positive climate in the home and classroom, that parental presence in the school makes a positive contribution, and that generally good interpersonal relations prevail between parents and teachers. In the view of the research participants, all these contribute to the successful adjustment of first graders, and are consistent with Bronfenbrenner's theory that when systems affecting the child are coordinated, they allow for optimal development of the child and strengthen each other (Bronfenbrenner, 1986; Bronfenbrenner and Morris 2006). These findings reflect the current approach about the importance of collaboration between parents and teachers for the benefit of the child (Acar et al., 2019; Dockett and Perry, 2014; Greenbaum and Fried, 2011).

While perceptions were similar, differences were found in the expectations of parents and teachers regarding the amount and channel of communication between them. This finding is consistent with Gavish and Friedman (2007), who argue that the differences in perceptions between the parents and teachers may be rooted in the lack of clarity about the needs of each group, and/or insufficient sensitivity to the parents' and teachers' needs as individuals and groups.

One important difference is how each group perceives the subject of parental presence in the school. Both parents and teachers agree and accept that the physical presence of parents is vital at the beginning of the first grader's school year, but when physical presence is replaced by mediated communication, particularly via the telephone, a gap emerges between the desires and needs of the parents, teachers, and children. The parents expect more frequent and ongoing communication than what currently exists, while the teachers assert that the parents lack limits about the frequency of their contact. What's more, teachers view some of the phone calls with parents as lacking importance. The children speak clearly in favour of the physical presence of their parents in the school throughout the school year, not just during the adjustment period. This is consistent with Dayan's findings (2011) about the longing of preschool children for their parents to spend more time with them in the physical school and get to know it more intimately. The children, however, find ways to cope with their parents' physical absence by symbolic means and by creating meaningful relationships with their teachers. The children also expressed a desire to involve their parents in their learning and the products of their learning.

It is important to understand that, prior to this research, the school under study had no mechanism for parents and teachers to work through the issues in disagreement. Had it not been for this research, the first author as a head teacher would not have known what the parents think about contact with the teachers, and to what extent they long for ongoing, personal contact with the teaching staff beyond what they currently have. Furthermore, the teachers would not be aware of the importance the children ascribe to the physical presence of their parents throughout the school year or their need to share with their parents the products of their learning activities.

Another concern of the parents that appears in the findings relates to the bus rides between their homes and the regional school. Technically, the school handles the transport arrangements: The children are escorted to the bus stops, and supervised for orderly boarding. Although the school does not view this as an issue, parents have expressed considerable concern about it, which the school staff was not aware of. This is where many parents find it hard to grapple with their physical absence from the school and worry 
about the security of their children. Note that the children do not raise the subject of the bus in their interviews, nor does it concern them after the initial adjustment period. It is important, however, to raise this issue in discussions between the parents and teachers as a concern of the parents.

Parents and teachers express dissatisfaction when the issues of concern to them are not properly addressed by the school staff. This observation, which also appears in the research literature, was apparent to some extent in the findings of this research. Greenbaum and Fried (2011) argue that the school system is still fearful of the involvement of parents in the school system, which may explain the failure of the system - unaware of the parents' perspective - to address the needs of this group. The bus rides to school, for example, illustrate that each party has its own perspective: The school believes that the matter is being handled, therefore it is not raised in teachers' conversations with the parents. From the parents' perspective, however, this sensitive subject, which preoccupies and concerns them, does not get a hearing in the parentteacher exchanges.

From the teachers' perspective, their needs vis-à-vis parents are also not being addressed. The teachers want to set limits on contact with the parents, limits that they believe are not sufficiently clear or understood by the parents. The lack of dialogue on this issue between teachers and parents leads to criticism of the parents by the teachers, criticism that could undermine relations between them and cast a pall on the atmosphere in the classroom. The parents, on their part, speak of the need to increase the frequency of meetings or dialogue with the teachers, paying little regard to the teachers' needs to set limits on the frequency or the subjects discussed. Failure to address the need for limits ignores the needs of the teachers, who are subject to ongoing, frequent contact with a large number of parents.

For a partnership among the parents, children, and teachers to be authentic, the needs of each group must be addressed, hence it is important to ascertain the unrealized needs of each group through dialogue among the partners.

These broad subjects as well as the different needs of the parents are not adequately addressed, hence the importance of engaging in research that offers ways to deepen the relationship between school staff, parents, and children, and more adequately respond to the needs of the stakeholders (Pianta, Kraft-Sayre, Rimm-Kaufman, Gercke, and Higgins, 2001).

This kind of research should be conducted beyond first grade in the school studied and indeed in all schools as part of the ongoing educational praxis. This would mean conversations in every educational framework to clarify expectations - identifying and defining needs and monitoring the changing needs of children as they adjust to first grade and later. Identifying needs and clarifying the expectations of the parents, children, and teachers could facilitate creation of a work plan relevant for the entire school in each educational framework. For example, in the school in which this research was conducted, the need arose to think of ways to increase the physical presence of parents in the school, to provide more information to parents about the bus transport of their children, and especially to reach agreements acceptable to both teachers and parents about the frequency and channels of communication between them. The focus of the work plans may be different in other schools, in accordance with the needs that arise from clarifying the expectations of the stakeholders. What emerges from this research is the importance of creating agreedupon mechanisms for parents and teachers to resolve disagreements that may arise and a framework for clarifying the expectations of each side. It is important to note that it is the school's responsibility to institute regular communication mechanisms with parents and families. Addi-Raccah et al. (2018) found that in cases in which teachers overcome their fear of "strong" parents, the teachers can be perceived as "carriers of social change through a relational system.". It was suggested that teachers, led by influential principals, who form reciprocal relations with students' parents can have an improved impact on their communities.

In the case presented in this study the principal and vice principal (the first author) led the teaching staff and the parents to forming a real partnership that did not exist before the research. This partnership built a mechanism for checking the expectations of stakeholders and one that enabled adoption of actions to meet the children's, parents', and teachers' expectations. 
Perspectives of teachers, children, and parents on...

\section{Declarations}

Limitations of the Study: In light of the small number of respondents, the scope of this research was limited, and should be expanded to the entire school. Furthermore, only mothers responded to the questionnaires even though they were distributed to both mothers and fathers. In the future, greater efforts should be made to involve fathers in the study and hear their perspective. The findings could help create a partnership of teachers, parents, and children with a more contemporary perception of school as a safe space that conveys a sense of belonging and in which the child develops abilities to meet complex needs. The involvement of parents and teachers together can create a real partnership that will enhance learning and the motivation to learn for the benefit of the children (Israel Ministry of Education, 2001; Sagi-Schwartz and Gini, 2008).

\section{References}

Acar, I. H., Veziroğlu-Çelik, M., Çelebi, Ş., İngeç, D., \& Kuzgunet, S. (2019). Parenting styles and Turkish children's emotion regulation: The mediating role of parent-teacher relationships. Current Psychology, 1-11. doi:10.1007/s12144-019-00390-y

Addi-Raccah, A., \& Ainhoren, R. (2009). School governance and teachers' attitudes to parents' involvement in schools. Teaching and Teacher Education, 25(6), 805-813.

Addi-Raccah, A., Amar, J., \& Ashwal, Y. (2018). Schools' influence on their environment: The parents' perspective. Educational Management Administration and Leadership, 46(5), 782-799.

Britto, P. R. (2012). School readiness: A conceptual framework. New York: UNICEF. Retrieved from https://www.unicef.org/earlychildhood/files/Child2Child_ConceptualFramework_FINAL(1).pdf

Bronfenbrenner, U. (1979). The ecology of human development experiments by nature and design. Cambridge MA: Harvard University Press.

Bronfenbrenner, U. (1986). Ecology of the family as a context of human development: Research perspectives. Developmental Psychology, 22(6), 723-742.

Bronfenbrenner U., \& Morris P. A. (2006). The bioecological model of human development. In R. M. Lerner and W. Damon (Eds.), Theoretical models of human development. Vol. 1 of the Handbook of child psychology (5th ed.) (pp. 793-828). New York: John Wiley \& Sons.

Dahlberg, G., Moss, P., \& Pence, A. (2013). Beyond quality in early childhood education and care languages of evaluation. London and New York: Routledge, Taylor and Francis Group.

Dayan, Y. (2011). Haperspektiva shel yeladim veyeladot 'al hameyda' shera-uy leha' avir lahorim 'al hana' asah bagan [The perspective of girls and boys about the information that should be given to parents about what takes place in preschool]. Hokrim@Hagil Harakh $1 . \quad$ Retrieved 12.8.2017 from http://sites.levinsky.ac.il/wordpress/kindergarten/wpcontent/uploads/articles/yaeldayan.pdf .

de Rivera, J. H. (1992). Emotional climate: Social structure and emotional dynamics. In K. T. Strongman (Ed.), International review of studies on emotion (pp. 197-218). New York: John Wiley \& Sons.

Dockett, S., \& Perry, B. (2007). Transitions to school: Perceptions, expectations, experiences. Sydney: UNSW Press

Dockett, S., \& Perry, B. (2009). Readiness for school: A relational construct. Australasian Journal of Early Childhood, 34(1), $20-26$.

Dockett, S., \& Perry, B. (2014). Continuity of learning: A resource to support effective transition to school and school age care. Canberra: ACT - Australian Department of Education.

Erez, T., Bienstock, O., \& Lukes, R. (2005). Kol hagan bamah: Mekomah shel haganenet betipuah regesh hevrati vekidum yahasim eykhutiyim began hayeladim [All the preschool's a stage: The role of the teacher in fostering socioemotional development and quality relationships in the preschool]. Hoveret Lehanhayat kvutzot gananot/Ministry of Education Publications, Pedagogical Administration, Pedagogical-Counseling Service.

Friedman, I. (2010). Yahasei beit sefer, horim, vekehilah beyisrael [School, parents, and community relations in Israel]. Website of the Initiative for Applied Education Research, Israel Academy of Sciences and Humanities. Retrieved from http://education.academy.ac.il/ .

Gavish, B., \& Friedman, I. (2007). Hamoreh keadam irguni: Trumata shel svivat ha'avodah hanitpeset 'al yedei hamoreh lenibuy hashhikah betehilat shnat hahora-ah harishonah uvesiyumah [Teachers as organizational people: The contribution of the work environment as perceived by the teacher to predict burnout at the beginning and end of the first year of teaching] Iyunim beminhal uve-irgun hahinukh / Studies in Educational Administration and Organization, 29, 55-87.

Greenbaum, C., \& Fried, D. (Eds.) (2011). Kishrei mishpahah: Misgeret hinukh begil harakh (gan-3): Temunat matzav vehamlatzot. [Familypreschool (K-3) collaboration: Review and recommendations]. Jerusalem: The Initiative for Applied Education Research, Israel Academy of Sciences and Humanities.

Hughes, J. N., Luo, W., Kwok, O., \& Loyd, L. K. (2008). Teacher-student support, effortful engagement, and achievement: A 3-year longitudinal study. Journal of Educational Psychology, 100(1) 1-14.

Israel Ministry of Education (2001, 1 December). Hozer Mankal 2/4 [Director-General's Directive 2.4]. Retrieved from 
http://cms.education.gov.il/EducationCMS/applications/mankal/arc/sb4h2_3_1.htm.

Mayring, P. (2000). Qualitative content analysis. Forum: Qualitative Social Research, 1(2) Art. 20. Retrieved from http://217.160.35.246/fqs-texte/2-00/2-00mayring-e.pdf

Pianta, R. C. (1999). Enhancing relationships between children and teachers. Washington: American Psychological Association.

Pianta, R. C., Kraft-Sayre, M., Rimm-Kaufman, S., Gercke, N., \& Higgins, T. (2001). Collaboration in building partnerships between families and schools: National Center for Early Development and Learning's Kindergarten Transition Intervention. Early Childhood Research Quarterly, 16(1), 117-132.

Pianta, R. C., La Paro, K. M., \& Hamre, B. K. (2008). Classroom Assessment Scoring System ${ }^{\mathrm{TM}}$ : Manual K-3. Baltimore: Paul H. Brookes Publishing.

Plotnik, R., \& Eshel, M. (2007). Sefer Hagan [The preschool book]. Tel-Aviv: Hakibbutz Hameuchad and the Kibbutz / Movement Education Department.

Russo-Zimet, G. (2016). The metaphorical collage as a research tool in the field of education. Universal Journal of Educational Research 4(4), 802-811. doi:10.13189/ujer.2016.040417.

Sagi-Schwartz, A., \& Gini, M. (2008). Ma'agalei bitahon rigshiyim-hevratiyim bein yeladim umorim bemisgeret hinukh [Emotionalsocial circles of security between children and teachers in educational settings]. In P. Klein and Y. Yablon (Eds.). Mimehkar le'asiyah behinukh legil harakh [From research to practice in early childhood education] (pp. 67-89). Jerusalem: Israel Academy of Sciences and Humanities.

Sayers, M., West, S., Lorains, J., Laidlaw, B., Moore, T., \& Robinson, R. (2012). Starting school: A pivotal life transition for children and their families. Australian Institute of Family Studies, 90, 45-56.

Schechtman, Z., \& Busharian, O. (Eds.) (2015). Bein horim lemorim behinukh ha'al-yesodi [Parent-teacher relations in secondary education]. Jerusalem: The Initiative for Applied Education Research, Israel Academy of Sciences and Humanities.

Shlaski, S., \& Arieli, M. (2001). Mehagishah haparshanit legishot post-modernistiyot bemehkar hahinukh [Interpretive and postmodern approaches to educational research]. In N. Sabar-Ben Yehoshua (Ed.), Masorot vezramim bemehkar eikhuti [Traditions and trends in qualitative research] (pp. 31-76). Or Yehuda, Israel: Dvir.

Tal, C., \& Bar, T. (2011). Yahasei mishpahah ma'arekhet hahinukh minekudat mabat historit [Family-school relations in an historical perspective]. In C. Greenbaum and D. Fried (Eds.), Kishrei mishpahah: Misgeret hinukh begil harakh (gan-3): Temunat matzav vehamlatzot [Family-preschool (K-3) collaboration: Review and recommendations] (pp. 171-174). Jerusalem: The Initiative for Applied Education Research. Israel Academy of Sciences and Humanities.

Vogler, P., Crivello, G., \& Woodhead, M. (2008). Early childhood transitions research: A review of concepts, theory, and practice. Working Paper No. 48. The Hague: Bernard van Leer Foundation. Retrieved from http://oro.open.ac.uk/16989/1/Vogler_et_al_Transitions_PDF.DAT.pdf.

Walker, J. M. T., \& Hoover-Dempsey, K. V. (2015). Parental engagement and classroom management. In E. T. Emmer and E. J. Sabornie (Eds.), Handbook of classroom management (pp. 459-478). New York and London: Routledge.

Yin, R. K. (2009). Case study research: Design and methods (4 $4^{\text {th }}$ ed.). Thousand Oaks, CA: Sage Publications. 